\title{
Rockfall Management at the Savage River Mine
}

\author{
B.J. Hutchison Australian Bulk Minerals, Savage River Mine, Australia
}

M. Widelski Australian Bulk Minerals, Savage River Mine, Australia

\begin{abstract}
Rockfall hazards are an everyday risk in most open cut mines. This paper describes the management techniques used to assess and mitigate rockfall hazards at the Savage River Mine located in the high rainfall environment of the west coast of Tasmania.
\end{abstract}

\section{$1 \quad$ Introduction}

The Savage River Mine (Figure 1) on the west coast of Tasmania has been in operation since 1966 with a one year hiatus in 1995 during which an ownership change was made. The mine is located in a semitemperate rainfall environment which experiences approximately $2000 \mathrm{~mm}$ of rainfall a year. The majority of the heavy falls occur during the winter and spring but all months of the year can experience significant rainfall.

When Australian Bulk Minerals (ABM) reopened the mine in 1996 the original truck and shovel operation was changed to a truck and backhoe excavator scenario and the magnetite ore has since been mined from a series of open pits, each undergoing relatively narrow cutbacks.

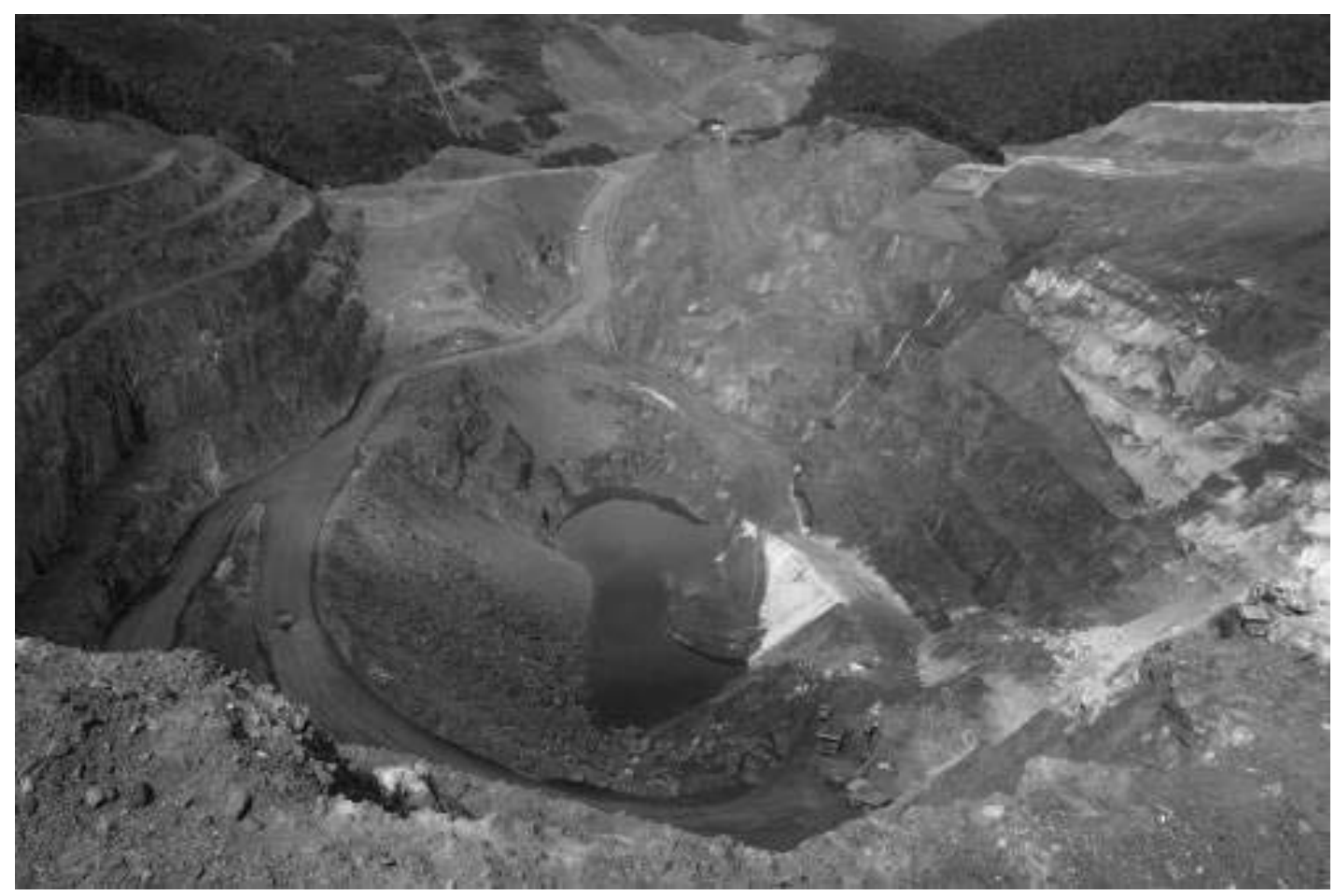

Figure 1 Savage River mine's north pit

Slope stability has been a major issue throughout the mine life, with large scale toppling and circular failures affecting mine schedules (Hutchison, 2000; Hutchison et al., 2002). These instabilities typically take place in weak chlorite schists or the highly sheared magnetite ore, which necessitate the adoption of relatively flat overall and intermediate slope angle designs, $\left(37\right.$ to $\left.40^{\circ}\right)$, refer to the general cross section and slope terminology in Figure 2. Fortunately these events typically take several months to develop and then undergo 
a more rapid failure over a day or two. The majority of these final failure events usually take place during the wetter winter and spring periods. The disruption to mining by such events has been mitigated by early recognition and planning.

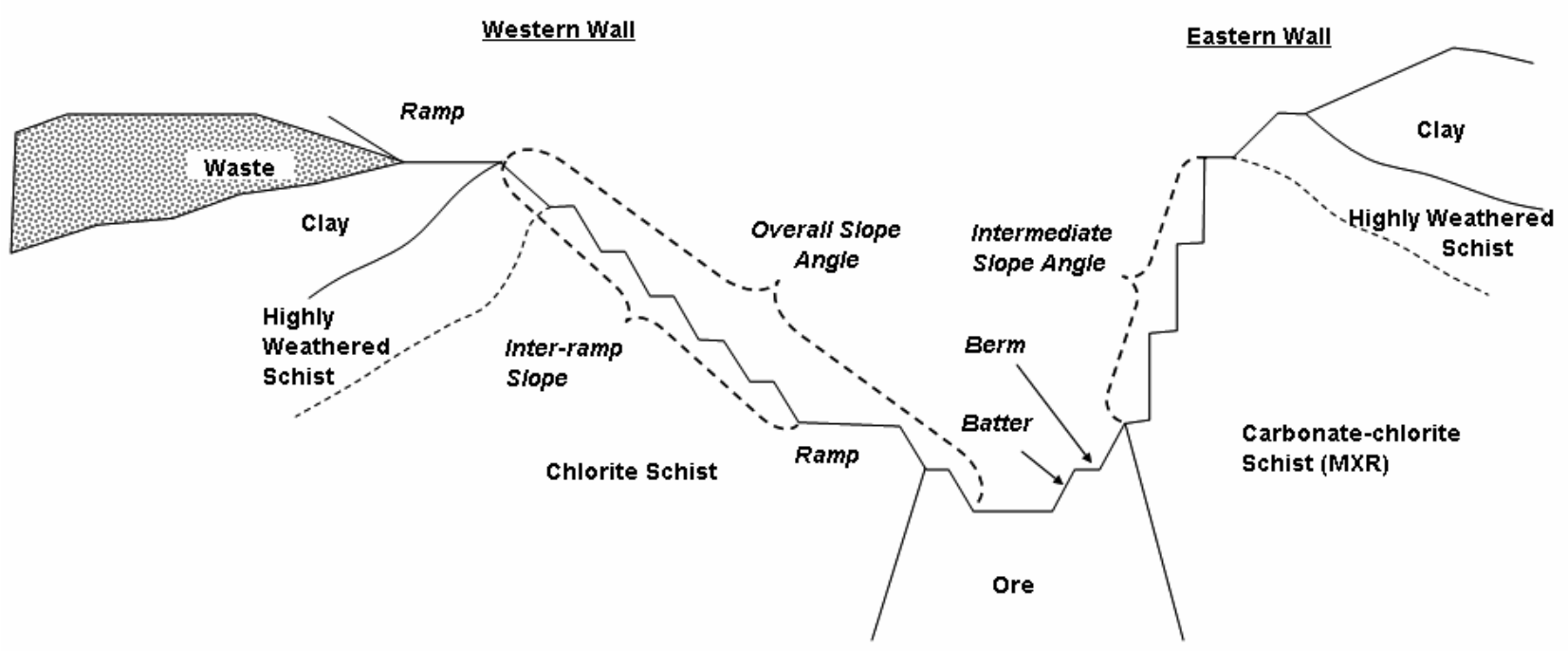

\section{Figure 2 North Pit geology and slope terminology}

In 2002/3 ABM made a decision to enter a five year closure plan that entailed mining the Centre Pit to a final depth of approximately $280 \mathrm{~m}$ and then the North Pit to a depth of over $300 \mathrm{~m}$. During the main Centre Pit phase (2004/05) extremely difficult mining conditions prevailed due to the development of a variety of large scale instabilities on the two long eastern and western walls. All of these unstable areas tended not to fail rapidly but gradually deteriorated, leading to a series of ravelling rockfall events directly related to excavation sequences and rainfall events. It was at this point in time that ABM became acutely aware of their inadequate work practices in relation to working near and under the high walls. The mine management then began a systematic review of all their mining procedures to ensure the risk, to firstly personnel and then equipment, was reduced to acceptable levels.

This paper describes the management techniques and practices used to assess and mitigate these rockfall hazards. Several 'soft' solutions where initially implemented, including heavy scaling, the use of 'safe operating procedures', exclusion zones and safety windrows. This progressed to the introduction of the remedial removal of large rock blocks, the installation of Geobrugg high energy catch capacity fences and an extensive cable bolting programme. Examples of successes and failures of these techniques are given.

ABM's mining operations has always had at least one full-time geotechnical engineering staff member, but this has been supplemented to have full time geotechnical coverage seven days a week. Daily geotechnical inspection of slopes and berms is standard practice. Slope movement monitoring has been carried out using Softrocks's automated prism tracking system (ATS) and more recently has been supplemented by GroundProbe's Slope Stability Radar (SSR) units. A discussion is included on the abilities and deficiencies of these instruments as used in the mining operation for both larger scale slope movements and for smaller rockfall events.

A long-term project is in progress to completely restrict access by personnel from a $20 \mathrm{~m}$ wide exclusion zone at the base of the high wall by providing remote equipment. To date two Atlas Copco L8 drills have been fitted with $60 \mathrm{~m}$ long umbilical cord controls, which have been operated from a small backhoe cab to remotely drill blast and cable bolt holes. In an advanced stage of development is the adaptation of a Merlo Roto 40.25 work platform to remotely load explosives. A brief overview of this project and its ultimate objectives is also included.

As the new high wall procedures and developments have taken some time to evolve, most of them were adopted after the Centre Pit operations were completed. This paper therefore goes on to describe the North 
Pit conditions, where they have been put into practice. With the recent mineral economic boom ABM have completed a Mine Life Extension Project study and are in negotiations with investors to extend the operations for a further 15 years. The adoption of this mine expansion will also have a significant mitigation effect on the rockfall problem as it will allow major changes to ore scheduling, thereby reducing exposure time under high walls in comparison to the 2009 closure plan.

\section{North pit eastern wall and rockfall developments}

The northern, western and southern walls of North Pit are comprised of the weak chlorite schists and sheared magnetite ore bodies. A series of slowly developing topples and circular failures have been experienced over the years in these walls but rockfalls have generally not been a problem. These walls have been designed at 37 to $45^{\circ}$ overall slope angles, with 50 to $60^{\circ}, 20 \mathrm{~m}$ high batter slopes, as depicted in Figure 2, to cope with the potential large scale problems.

The east wall is comprised of carbonate chlorite schist, designated MXR, which is metamorphosed, brittle and quite competent compared to the other mafic schists. The MXR has a steep easterly to vertical dipping foliation with the majority of the foliation being quite tight. There are few open joints encountered in diamond drill holes, although the rock breaks in a blocky to very blocky nature upon blasting. The block surfaces tend to be comprised of an orthogonal combination of chlorite foliation planes and clean or calcite coated joints.

As $\mathrm{ABM}$ progressed their mining operations through a series of cutbacks the eastern wall intermediate slope angle in the MXR rock has been steepened from 47 to $63^{\circ}$. The photo in Figure 1 and the cross section in Figure 2 show the stark slope design contrast between the eastern and western walls.

It is this eastern wall that has contributed mostly to the MXR rockfall problems discussed in this paper. Some rockfalls have been experienced on the northern wall but for the most part they have been sourced from the MXR, where it swings around to the west in the upper levels of the north eastern corner of the pit, or from a major fault zone at the MXR/ore contact.

The latest extension 3 cutback design had a series of $20 \mathrm{~m}$ vertical presplit batters with $10 \mathrm{~m}$ berms to give the $63^{\circ}$ intermediate slope angle. Unfortunately when the eastern wall was cut further back into the east wall, unfavourably oriented jointing was encountered over significant portions of the wall. These 40 to $60^{\circ}$ westerly dipping joints caused the partial or complete loss of some of the $10 \mathrm{~m}$ wide catch berms, as shown in Figure 3, creating ski jumps for potential rockfalls.

\section{Rockfalls}

Rockfalls from the east wall of North Pit are generally of two types. The first involves the loosening and toppling/sliding of large blocks or wedges from the batter face, refer to the example in Figure 4. These failures have often been instigated by blasting and several have been noticed within the first few minutes of a blast when the shot firers have been clearing the shot. In some cases the loosening of large blocks occurs over a long period of time and these can and have been identified by geotechnical inspections, for example Mat's Block, shown in Figure 5.

The second type of rockfall at Savage River involves small blocks of rock that get loosened by the blasting or are washed off the face during high rainfall events, refer to Figure 6 . The source of these smaller blocks is often material from the batter crests where the rock gradually opens up along the steep foliation due to relaxation.

In most cases the falling rocks usually came to rest within 15 to $20 \mathrm{~m}$ of the toe of the slope. At one point the geotechnical staff closed a portion of the pit and hand scaled crest rocks from the berm just above the "ski jump" joints shown in Figure 3. In this case the vast majority of rocks again fell within the $20 \mathrm{~m}$ zone, although about $3-5 \%$ of the total number reached out to $30 \mathrm{~m}$. 


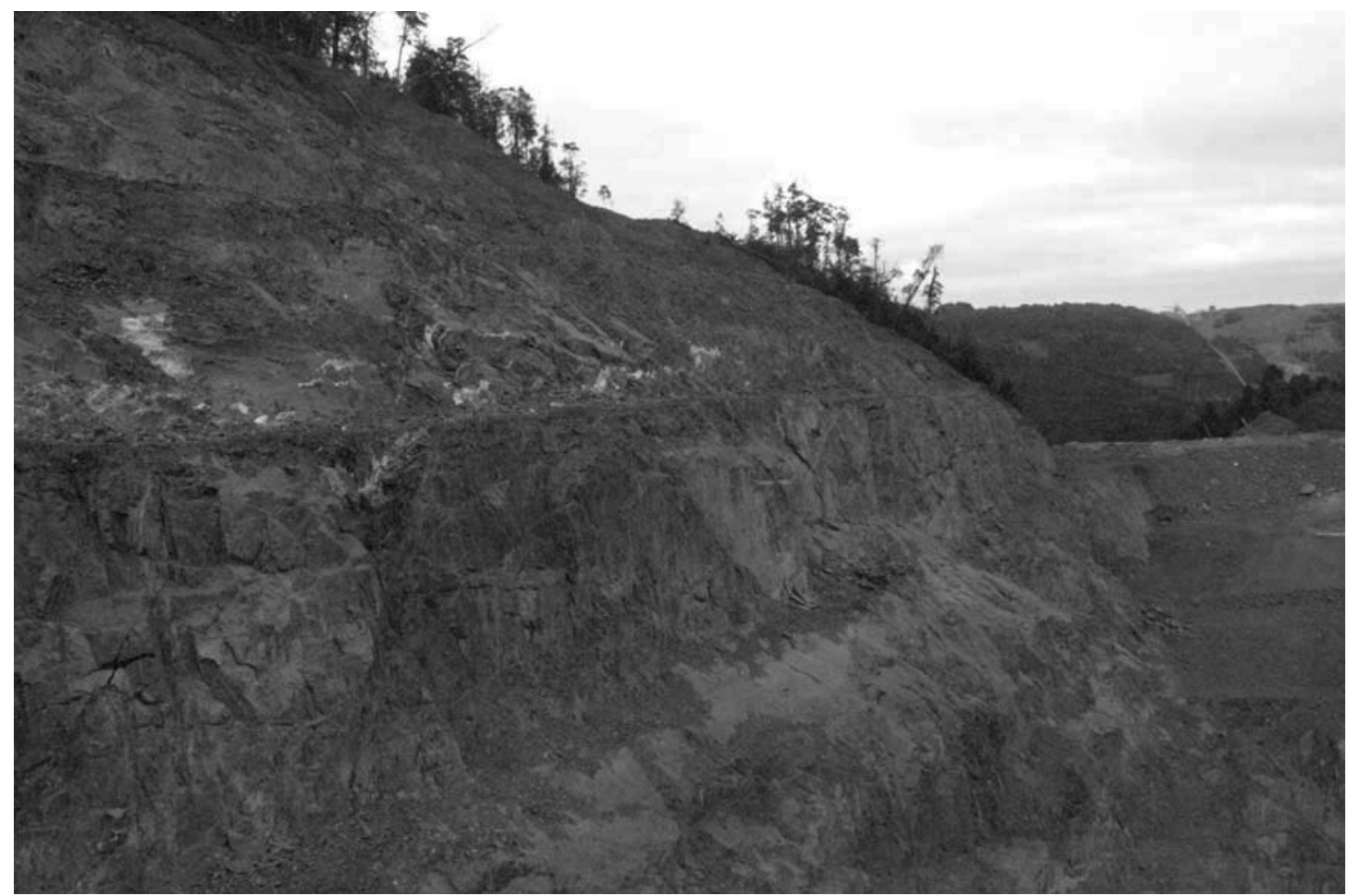

\section{Figure 3 North pit extension 3 berm loss due to unfavourable jointing}

\section{Rockfall mitigation}

\subsection{General}

To safely operate in the rockfall environment discussed above ABM reviewed and reinforced their safe work practices, which includes the following:

- The use of Job Safety Analysis (JSA) for any new task, including the carrying out of on the spot risk analysis, which all employees have been trained in.

- The development of Safe Operating Procedures (SOP) for all day to day tasks, again which all employees in that field are trained in and signed off on.

- The application of a $20 \mathrm{~m}$ wide exclusion zone at the toe of the slope, into which access is restricted unless a JSA and/or SOP with its accompanying risk assessment, has been completed. This usually includes an inspection by geotechnical staff.

- Seven day per week coverage by geotechnical staff to carry out bench and wall inspections, to operate the slope movement monitoring systems and to advise the design, planning and supervisory staff on pit and dump designs and progress.

These procedures might well be termed 'soft solutions' as they manage or reduce the risks but they do not eliminate them. ABM also employed additional 'hard' engineering solutions such as removal of potential rockfall blocks (by scaling and blasting), the cable bolting of the batter faces and the erection of high energy capacity rock catch fences.

These solutions are not risk free, nor are they full proof, so the most important decision made by upper management was to embark on a longer term programme to eliminate the exposure of personnel to the rockfall hazard by excluding personnel from the danger area at the toe of the high wall. To date ABM and their contractors have developed remote drilling capability into their Atlas Copco L8 drilling fleet and are progressing the development of a remote explosive loading system for their trim blasts. Examples of these operations are given below. 


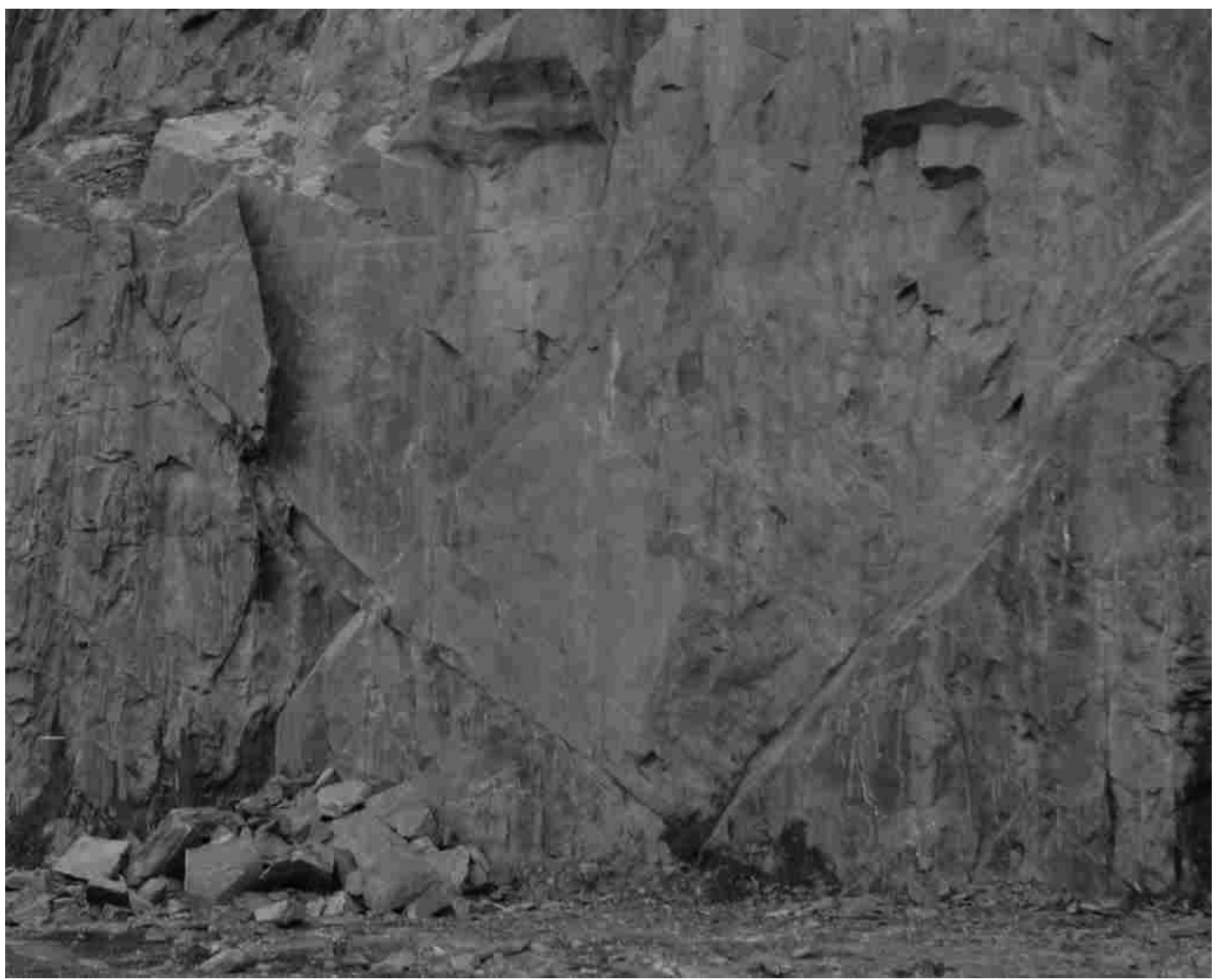

Figure 4 Rock block failure instigated by blasting

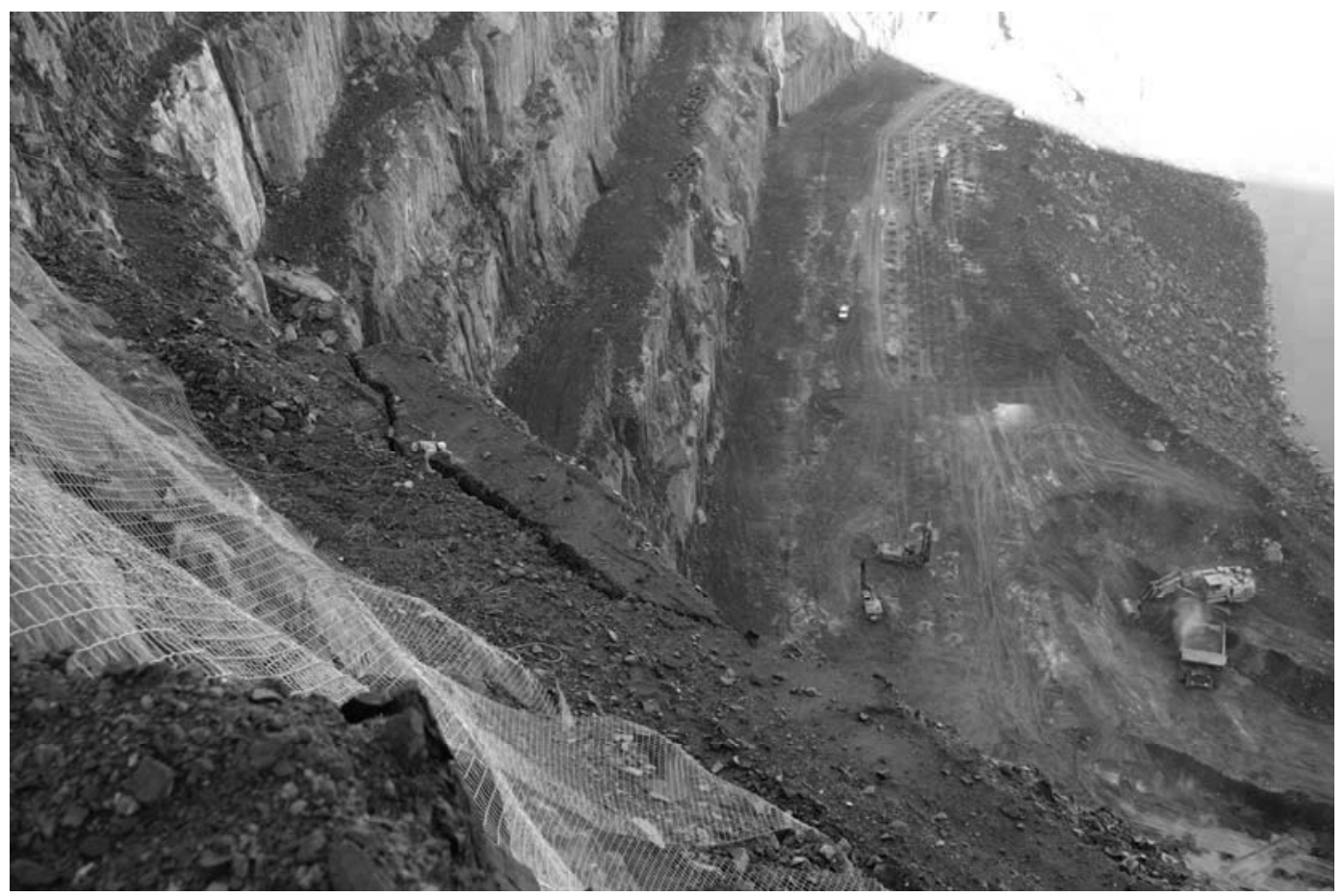

Figure 5 Long term loosening and toppling of Mat's Block (110 m above work area) 


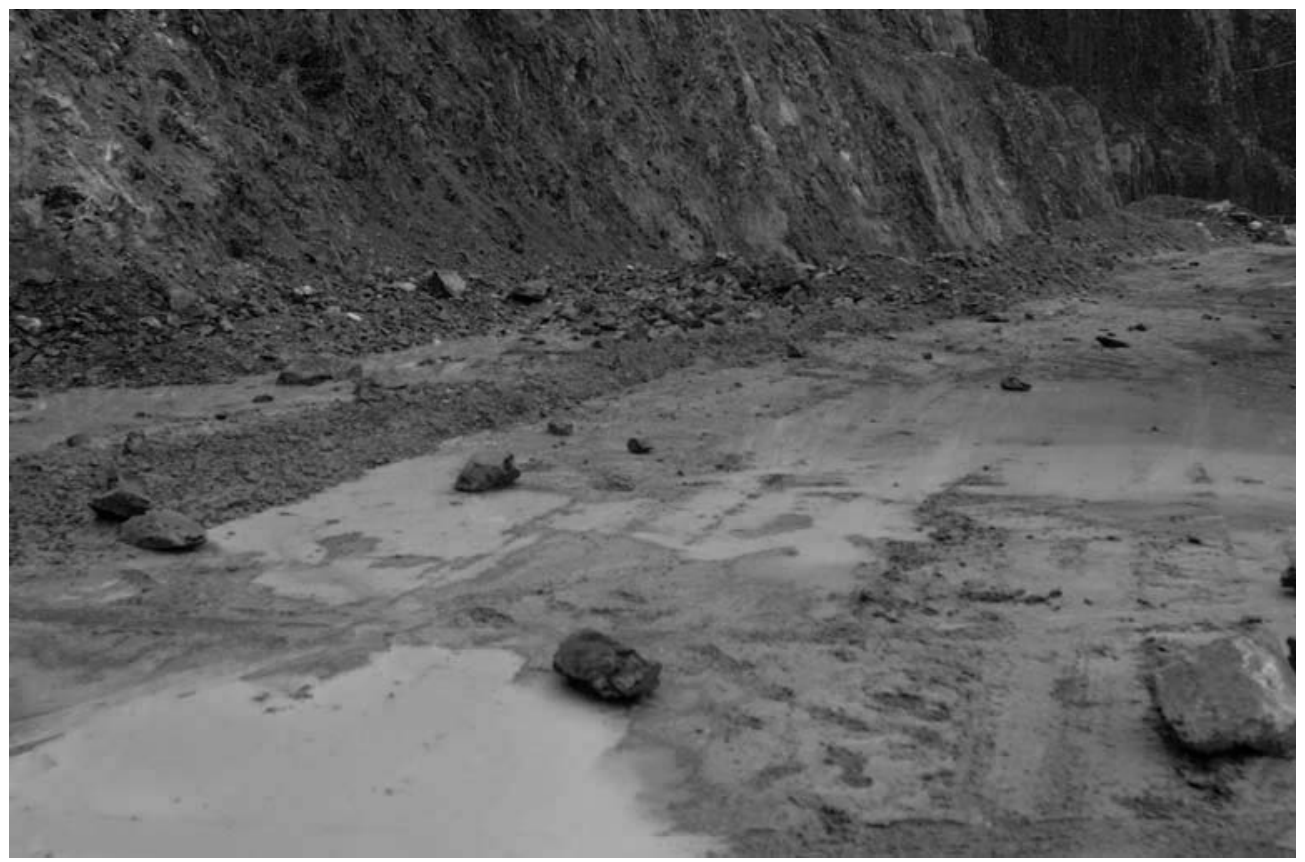

Figure 6 Rainfall induced rockfalls

\subsection{Rock block scaling and removal}

ABM have an intensive machine rock scaling programme that utilises an array of excavators from their main production machines (O\&K1200 and Cat 5130) down to specialist long reach excavators, such as the Cat 325L shown in Figure 7. In this figure a water cannon had also been attached to the excavator scaling bucket to wash loose rock from the face. This technique was trialled when a long dry spell was encountered that reduced the natural washing normally experienced by rainfall. Although it was relatively successful it has not yet been adopted as a standard procedure.

The machine scaling is usually carried out in two stages, one to scale the crest and another when the toe of the $10 \mathrm{~m}$ deep blast is exposed. In the case of the softer northern and western walls the crest scaling is generally just a light scale to roll over the crest and remove loose material. Any harder scaling could unwontedly dig well back into the berm.

In the eastern wall MXR unit the machine scaling of the crest was an aggressive effort to ensure any large wedges or blocks were removed. Until the unfavourable jointing was encountered in the latest cutback, only an occasional wedge was found and these were removed due to the lack of rock reinforcement installation capability of the production crews. The aggressive scaling of the crests usually rounded off no more than one to two metres of the 8 to $10 \mathrm{~m}$ wide benches, leaving rock catchments for most of the rockfalls being experienced at that time.

With the advent of the unfavourable jointing the aggressive scaling began to remove all, or a significant portion of the $10 \mathrm{~m}$ wide benches, leaving no effective rock catching capability. It was however deemed prudent to ensure these blocks or wedges were removed at the time as it was very expensive or nearly impossible to go back up at a later date to remove loosened material.

ABM has also made an unsuccessful attempt at trying to employ rock climbers to effectively remove small loose blocks of rock from crest and batter areas. Due to access and base anchor placement problems this proved to be inefficient from both a cost and scheduling view point. Mat's Block, shown in Figure 5, was however successfully removed by blasting, see Figure 8, and then draping curtain mesh over the resulting face, see Figure 9. The block was approximately $20 \mathrm{~m}$ long, $2 \mathrm{~m}$ wide and 10 to $15 \mathrm{~m}$ in height. The job was complicated by a lack of access directly onto the block, with only walking access to the berm $15 \mathrm{~m}$ above. The block had been monitored for over a year, using photographs taken from the berm above to estimate changes in the crack development. The photographs were taken at intervals varying from daily to weekly depending on weather and blasting under the block. 
Although there was no evidence of imminent failure the decision was finally taken to remove the block. After gaining access down onto the block via ropes and ladders it was deemed too risky to drill blast holes directly in the block itself, for fear this could destabilize the block during the drilling process. The explosives therefore needed to be packed directly into the crack; so there was the possibility of having a very disturbed back scarp following blasting. "Rocklink" curtain mesh was therefore deemed necessary to allow any loose and dislodged rocks to be directed down onto a berm $40 \mathrm{~m}$ below.

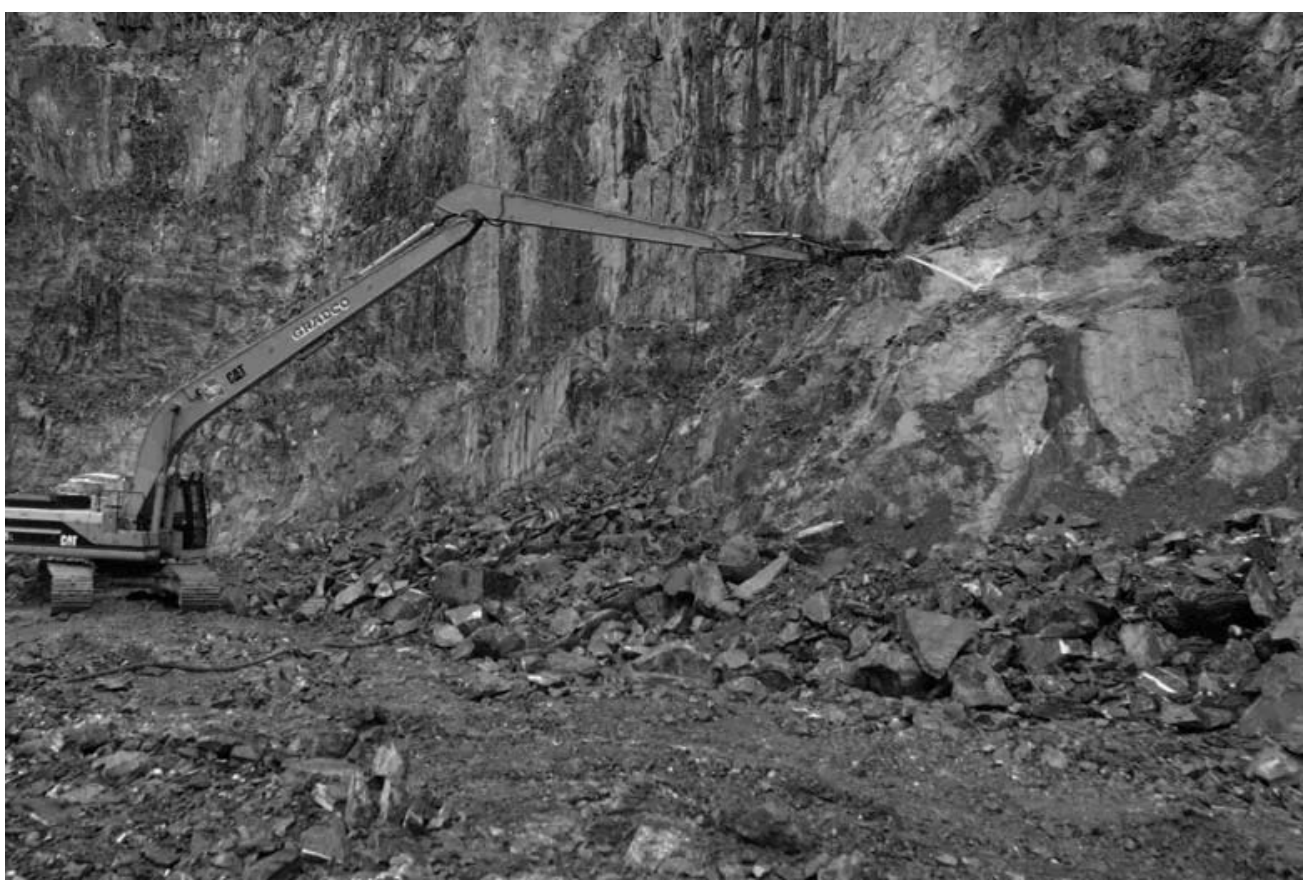

\section{Figure 7 Longreach excavator with washing attachment}

A helicopter was utilized to transport the mesh material and a pneumatic drill was used to place pins on the berms to hold the mesh. This work was supervised and carried out by Rock Engineering Pty Ltd with assistance from Earthtec Constructions Pty Ltd and site personnel. The curtain mesh was attached to the back of the berm and left rolled up before the explosives were loaded and fired. The $50 \mathrm{~m}$ long rolls of mesh were then released and stitched together by Earthtec personnel whom rappelled down over the mesh. The removal of Mat's Block was successfully carried out but at a cost of approximately A $\$ 200,000$.

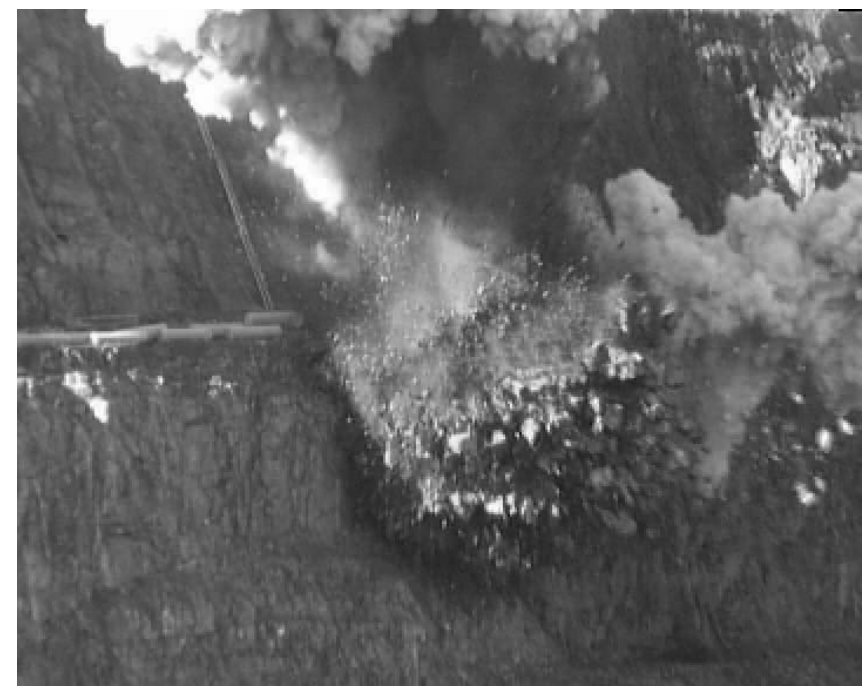

Figure 8 Blasting of Mat's Block 


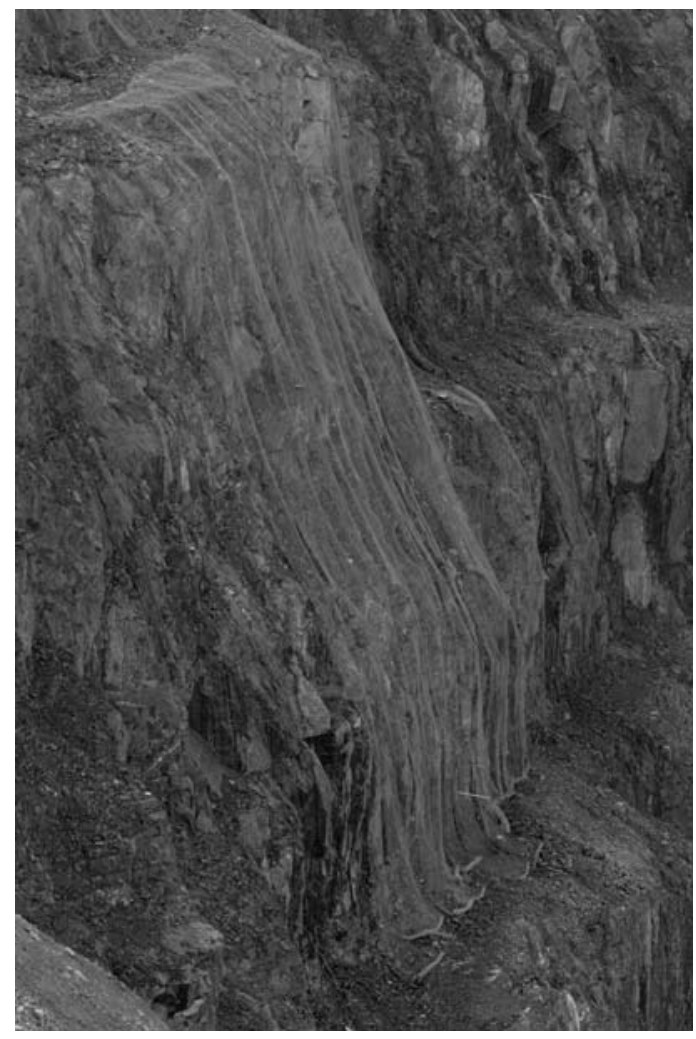

Figure 9 Mesh draped over remnant of Mat's Block

\subsection{Rock catch berms and fences}

It started to become obvious that significant lengths of the $10 \mathrm{~m}$ wide berms were not standing up, and the catch capacity of the east wall was no longer adequate to protect workers at the bottom of the pit. In an attempt to improve catch capacity, a $20 \mathrm{~m}$ wide catch berm was designed at the 200RL. To achieve this, the catch benches above (220RL) and below (180RL) were both reduced, to $5 \mathrm{~m}$ widths, effectively creating double batters above and below. It was intended that the 200RL berm should have a $2 \%$ grade towards the south to control the runoff water that washed down the east wall. This was partially successful, at the northern end of the bench, as shown in Figure 10, but unfavourable jointing at the southern end of the bench resulted in the loss of the crest and thus the controlled drainage. In one section used haul truck tyres were pinned and cable bolted then backfilled to make an artificial crest, refer to Figure 10. This has since captured several small rockfalls.

Due to the failure to effectively create a wide catch berm all the way along the pit it was obvious that alternative rockfall mitigation measures were needed. Following an assessment of alternatives, a series of Geobrugg high energy rock catch fences totalling $600 \mathrm{~m}$ in length were supplied by and installed under the direction of Rock Engineering Pty Ltd. The rock catch fences were of two capacities: $250 \mathrm{KJ}$ and $500 \mathrm{KJ}$; and varied in height from 3 to $5 \mathrm{~m}$. The distribution of these variable height and capacity fences was based on a risk analysis of the east wall, taking into consideration factors such as previous rockfall activity, concentrated surface water flow areas, loose rock areas and, condition of existing berms. In addition, computer simulations of rock falls down typical east wall profiles were carried out to assess the typical rock fall trajectories, to assist in evaluating the required fence heights.

These fences are often used on highways to prevent rocks cascading out of ditches and across the road surface. In the mine, they are required to be placed as far from the wall as possible, but not too close to the crest to be effected by the next presplit blasting and underlying batter. A $15 \mathrm{~m}$ wide berm was designed and $3 \mathrm{~m}$ deep postholes were drilled $7 \mathrm{~m}$ behind the lower presplit crest, on $10 \mathrm{~m}$ centres. To protect the crests, $8 \mathrm{~m}$ single strand passive cable bolts were drilled at $45^{\circ}$ into the berm, $3 \mathrm{~m}$ back from the presplit line. This configuration was very successful over $330 \mathrm{~m}$ of the initial $450 \mathrm{~m}$ of fence, refer to Figure 11. 


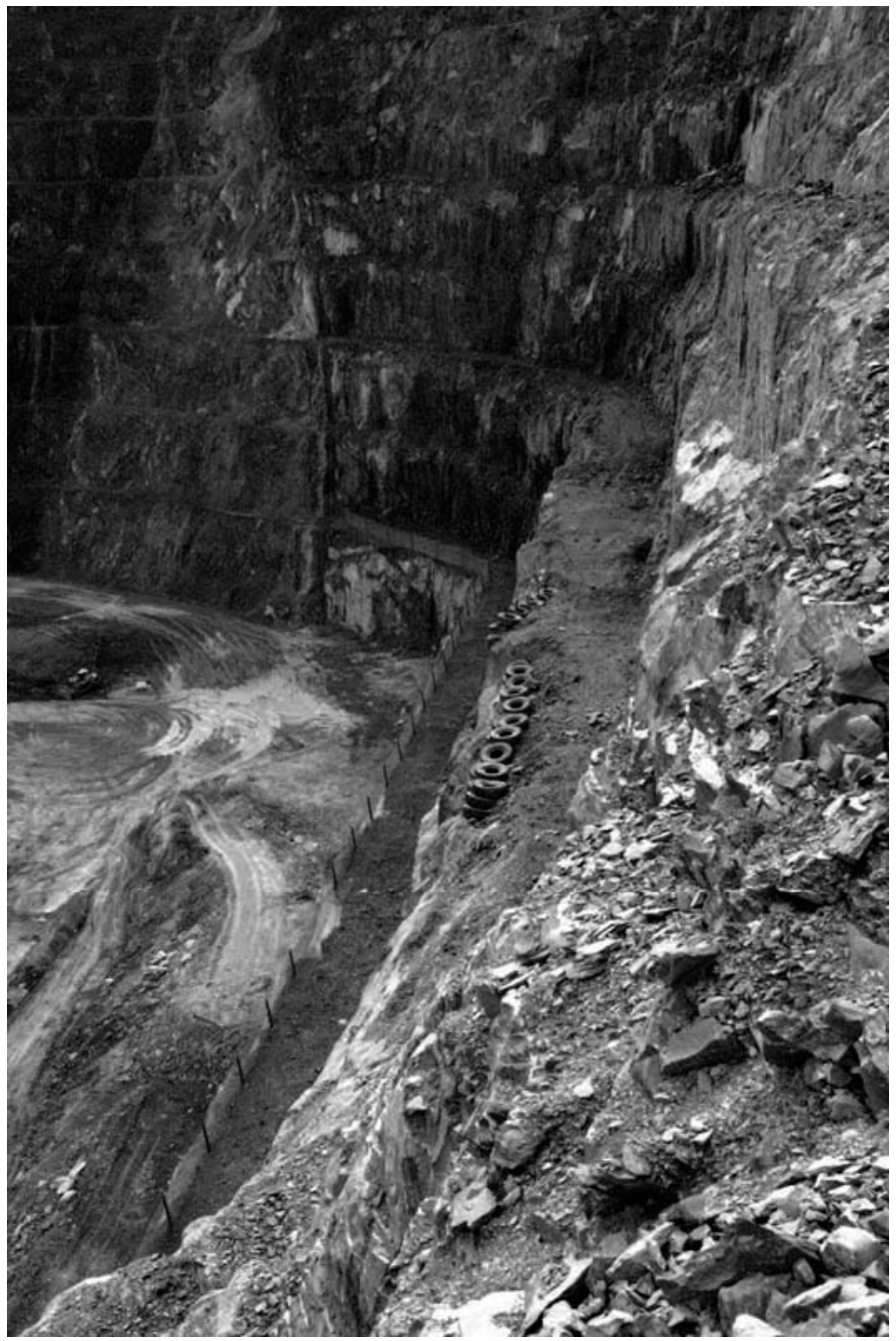

Figure 10 RL 200 catch berm (with tyre wall) and RL160 rock fence below

Of the remaining $120 \mathrm{~m}$, about $80 \mathrm{~m}$ was undermined where the crest failed, requiring the dismantling of the full $120 \mathrm{~m}$. The remaining $150 \mathrm{~m}$ of fence and the $120 \mathrm{~m}$ of dismantled fence were erected on berms further to the south or down the slope. In both cases $10 \mathrm{~m}$ long shear pins were placed on $5 \mathrm{~m}$ centres and the fence posts attached to every second shear pin. The shear pins were $100 \mathrm{~mm}$ universal steel sections grouted into $220 \mathrm{~mm}$ holes. This was partially successful, but another $60 \mathrm{~m}$ of fence was lost due to crest failure where the shear pins failed. It was subsequently recommended that larger $300 \mathrm{~mm}+$ diameter holes be drilled and that concrete rather than grout be used.

To allow protection during cable bolting and remote drilling activities, a mobile rock catch fence with a $50 \mathrm{KJ}$ catch capacity, using Tecco mesh, was designed by Rock Engineering Pty Ltd and Combined Resource Engineering Pty Ltd. The fence is moved by the in-pit dozer and is placed between the high wall and the grouting crew, or between the remote drill and the backhoe control unit, refer to Figure 12. The combined cost of the $600 \mathrm{~m}$ of rock catch fence and the mobile fence was approximately $\$ 1.8 \mathrm{M}$ Australian, including all the drilling, crest cables and shear pins. On several occasions small rocks disturbed by blasting have been observed hitting the fence and then coming to rest on the berm behind it. There are also two cases of larger block failures that have also been caught up in the fence and been prevented from reaching the lower working areas. 


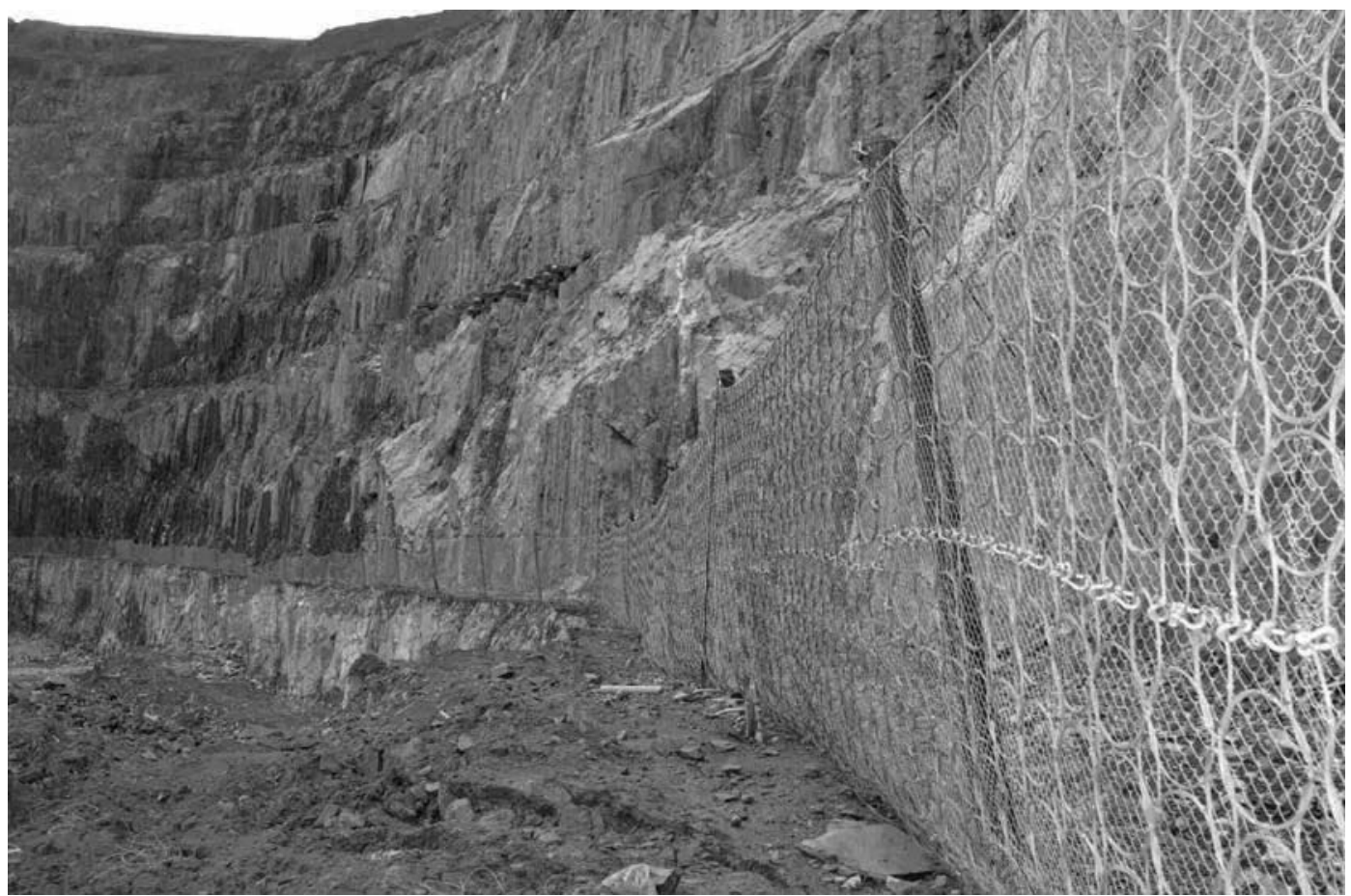

Figure $11250 \mathrm{KJ}$ Geobrugg rock catch fence

\subsection{Cable bolting}

When the rock catch fence was erected and the vertical batters were exposed it became imperative that crest or batter sized failures did not occur causing any further undermining of the catch fence. A programme of cable bolting was therefore undertaken on the batter slopes below the rock catch fences. Fifteen metre long, twin strand, $50 \mathrm{t}$ passive cable bolts were placed at variable spacings, depending on the geologic structure. A line of bolts, spaced $1.5 \mathrm{~m}$ to $2 \mathrm{~m}$ apart were placed along each $3.5 \mathrm{~m}$ excavation flitch, although massive rock conditions allowed some rows to be eliminated, along with the last row above each berm. In general, straps and mesh were not extensively used due to the need to wait till grout set before allowing tensioning, thereby delaying the mining cycle. Single hole, $300 \times 300 \mathrm{~mm}$ face plates were lightly tensioned to one of the two strands; which was a relatively quick operation.

Occasionally rock block failures, such as that shown in Figure 4, occurred, but most were in unbolted ground. The bolting was carried out by mine site personnel. The drilling of the cable bolt holes was carried out remotely as described in Section 4.5. To reduce the risks to the grouting crew, geotechnical inspections were made before each grouting session, a GroundProbe Slope Stability Radar was also used to monitor rock movements (see Section 5) and the mobile rock catch fence was placed between the rock face and the men and equipment.

\subsection{Remote drilling}

In ABM's quest to create a $20 \mathrm{~m}$ wide exclusion zone at the base of the high wall they first addressed the drilling task, as a significant period of time was required to drill the presplit holes as close as $2 \mathrm{~m}$ to the toe of the batters. When ABM was incapable of finding an off-the-shelf remote drilling rig capable of meeting their requirements they funded the local drilling contractor Maxfield Drilling to adapt one of their Atlas Copco L8 drill rigs. Radio remote controlled equipment usually has approximately a dozen remote functions but the L8 had up to fifty nine functions that needed to be remotely controlled. The contractor therefore adopted low tech, less expensive cable remote technology, which allows for a multitude of functions, governed only by the amount of data that can be passed through the cable. The cable system was designed so that it could be plugged/unplugged as required, using up to $60 \mathrm{~m}$ lengths of multi-core cable to enable the operator to be a safe working distance from the high wall. The operator now sits in an air conditioned, small backhoe unit with the control panel as shown in Figure 12. 


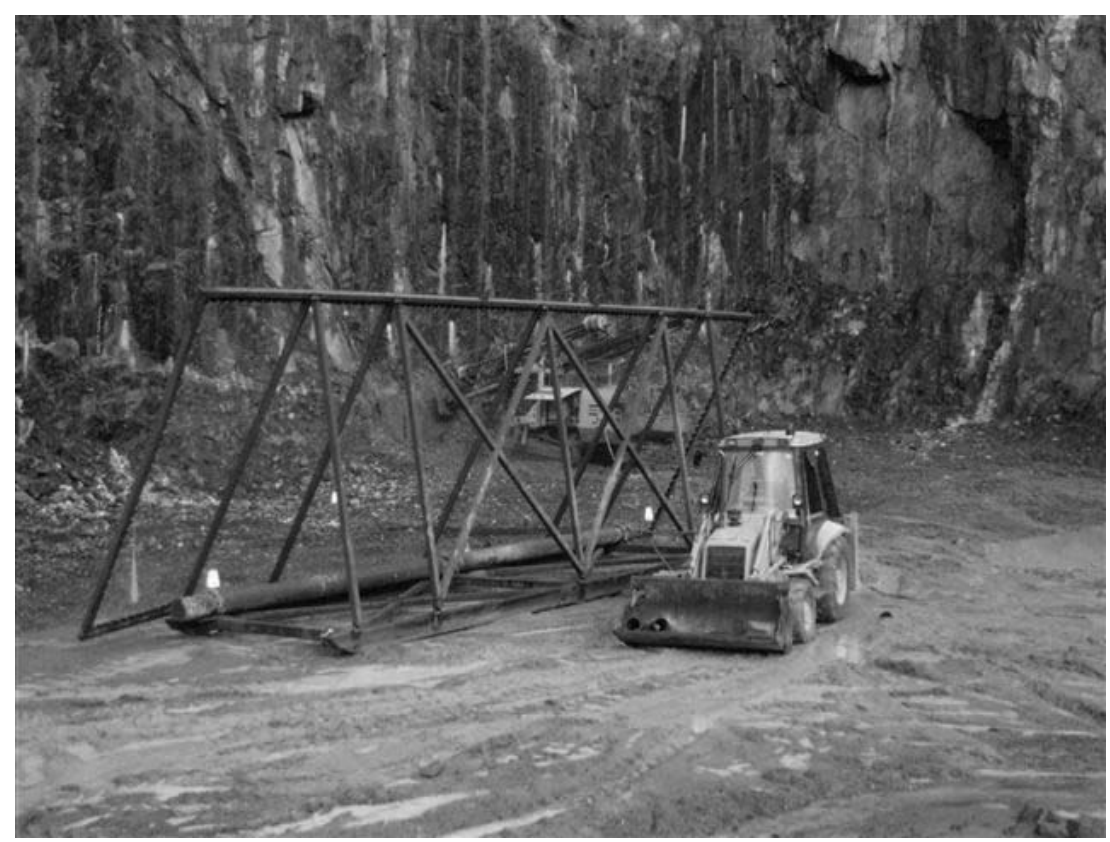

Figure 12 Mobile rock catch fence in use during remote drilling

\subsection{Remote loading and the REL project}

ABM's risk analysis of high wall procedures identified that of all the pit employees, the drill and blast crew spent the most time directly under the high wall, especially when loading presplit and trim shots. Following the success with the remote drilling a decision was made to set up the Remote Explosive Loading (REL) project. The REL project involves the development of procedures and equipment to allow the trim blasts to be loaded from outside the $20 \mathrm{~m}$ high wall exclusion zone.

A detailed review of the current procedures identified the following tasks that required personnel to enter the exclusion zone:

- Setting out the blast hole markers.

- Surveying the blast hole positions for hole depth.

- Dipping the blast hole.

- Priming the blast hole.

- Loading the blast hole.

- Stemming the blast hole.

- Tying up the blast pattern.

After assessing various alternatives and pieces of equipment, the project is now directed at developing a series of four attachments to a Merlo Roto 40:25 slewing handler (Figure 13) to allow these tasks to be carried out from outside the $20 \mathrm{~m}$ exclusion zone. This machine has a total reach of $22 \mathrm{~m}$ with a $150 \mathrm{~kg}$ load.

The first attachment will drop markers on the individual drill hole locations and allow the surveyor to determine the collar elevation and required blast hole depth from outside the exclusion zone. This stage can be eliminated when GPS capabilities become available at the mine and can be directly integrated into the remote drilling procedure.

The second attachment is a hose reel to be permanently attached to the Merlo boom. It will be connected to the explosive delivery truck via a 10 to $20 \mathrm{~m}$ delivery hose. The third attachment will be a roller assembly that drives the bulk explosive hose down the hole. It will have a depth measuring device and the initiating product delivery system. The fourth attachment is the stemming bucket. This is designed to load four holes 
before being refilled by the current stemming loader, outside the exclusion zone. At the time of writing all these attachments are in the process of being designed or manufactured.

A risk assessment for the project has been compiled and is regularly updated. Task and Job Safety Analyses are being done with the intent to further review them as each attachment is trialled. Both Orica (the explosive supplier) and Workplace Standards Tasmania are currently looking at the Merlo and the designs for the Hose Reel and Initiating Explosive delivery system as part of the approval and compliance processes.

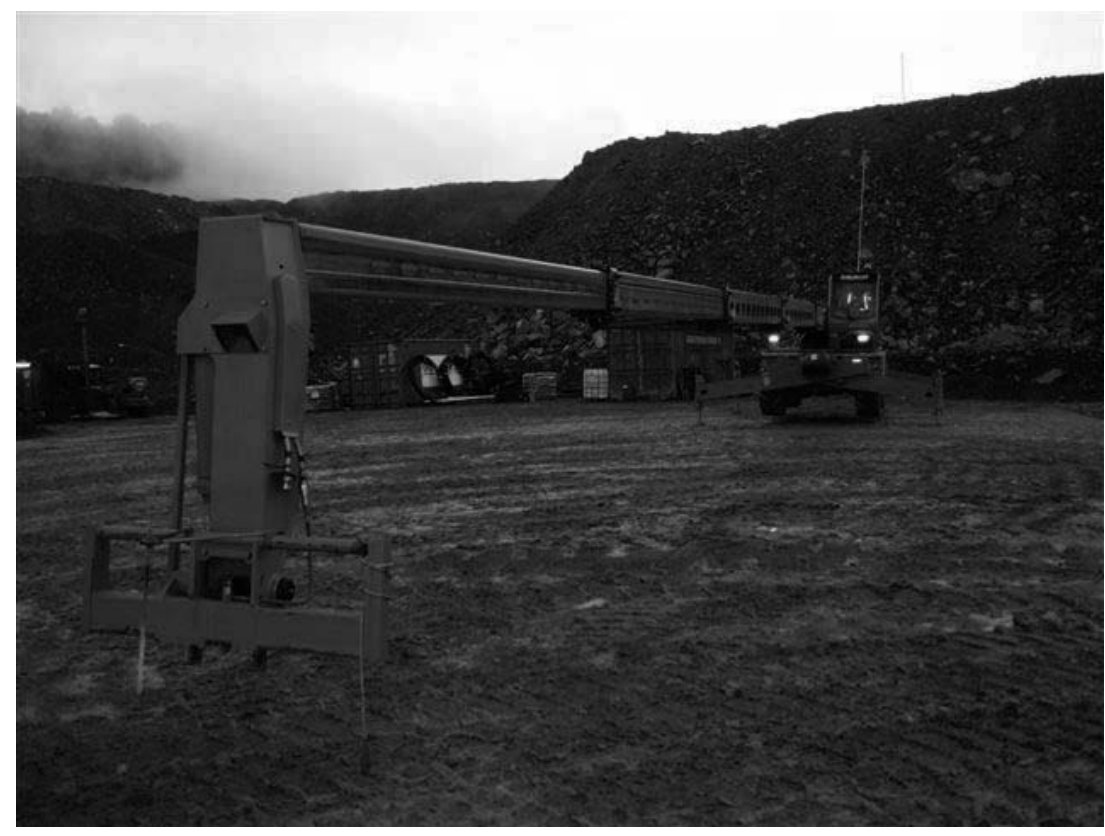

Figure 13 Merlo Roto 40:25 for remote explosive loading

\section{$5 \quad$ Slope monitoring}

Until recently high wall monitoring at Savage River has been carried out through visual inspections and by prism monitoring. The prism surveys were initially carried out by the mine surveyors, but in 2003 Softrock Solution's automated tracking system (ATS) was introduced, and has performed well. The prism monitoring systems are an integral part of ABM's monitoring programme and the ATS system in particular has provided automated scheduling of surveys and off site access to the control and viewing features. The ATS system has given movement accuracies of $+/-2 \mathrm{~mm}$ over much of the North Pit.

The ATS had been adequate for monitoring movements in the softer material. When rockfalls and block failures started to occur in the brittle MXR material, associated with the unfavourable jointing, alternative monitoring arrangements were required. Several potential wedge shaped failure blocks have had prisms grouted into them on the rock faces, but most of them have been damaged or destroyed by blasting in their immediate vicinity, so the ATS has not been a practical tool for these types of brittle rock failures.

The limitations with the prism monitoring system were highlighted on 30 October 2006, when $400 \mathrm{t}$ of rock fell onto a blasted shot just prior to shift change. The wall failed two and a half hours after the afternoon blast. The area had been visually inspected by the geotechnical engineer and the assistant pit superintendent, before a dozer, surveyors and drill and blast supervisors moved into the area. The wall gave no indication (visible to the naked eye) of failure and the nearest prism was over $50 \mathrm{~m}$ away.

GroundProbe's Slope Stability Radar (SSR), see Figure 14, with its sub $0.2 \mathrm{~mm}$ movement accuracy and alarm capabilities, was therefore trialled to see if it could identify potential rockfall areas. The radar was retained beyond the trial date due to its ability to monitor minute movements over a medium to large area in real time. The biggest limitation with the radar has been that it could not monitor movements of smaller blocks $\left(<4 \mathrm{~m}^{2}\right)$ that might fall from the wall at the distances that the radar could most practically be deployed. 


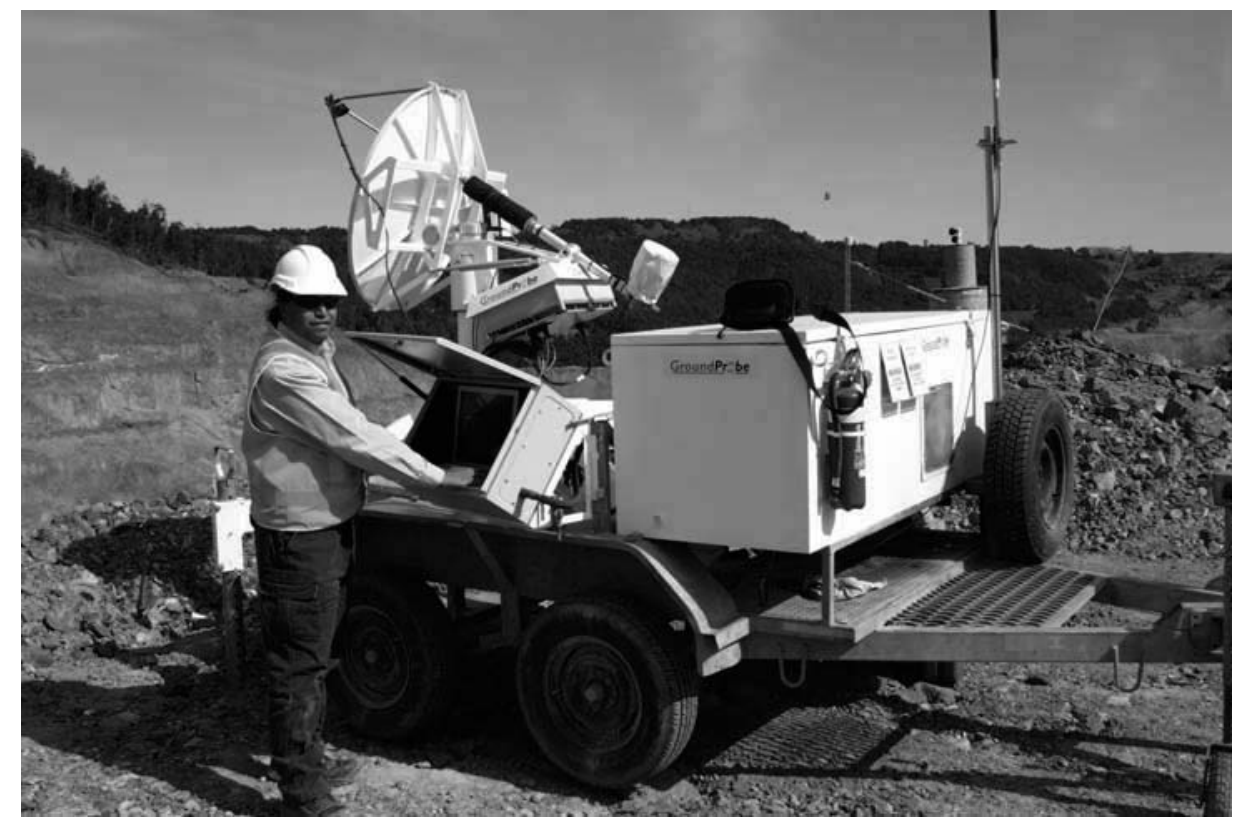

\section{Figure 14 GroundProbe's slope stability radar}

Data resolution is a function of the frequency the radar operates at and the distance that the radar is from the target. The radar progressively scans along a wall taking measurements with the radar beam at each point. The closer the radar is to the wall the smaller the beam (or pixel size) of the area being measured. At $60 \mathrm{~m}$ this is approximately $1 \mathrm{~m}^{2}$, whereas at 600 to $800 \mathrm{~m}$ the pixel size spreads out to 50 to $80 \mathrm{~m}^{2}$.

To accurately monitor and interpret movements it is recommended that several adjacent pixels fully or partially fall within the moving block so that more than one pixel shows movement to assist in the interpretation. Theoretically to identify movement of a 1 to $2 \mathrm{~m}$ wide block one would require a pixel size of approximately $1 \mathrm{~m}$ or smaller. This could possibly be achieved by placing the system very close to the wall or by deploying an alternative radar model such as the SSR-X. The SSR-X has a longer monitoring range and at a similar distance to the SSR, a significantly smaller pixel size.

In the case of Savage River the wall of interest was directly adjacent to the main mining operations, where the radar would be exposed to regular (usually daily) blasting. Due to the typical two hour time delay caused by clearing the blast, moving fly rock and setting up the equipment, it would be unlikely that the radar would be able to monitor any rock falls or wall movement directly after the blast.

With the inability to deploy the radar close to the targeted east wall, the radar unit was set up on the top of the western wall at a range of 600 to $800 \mathrm{~m}$. At this distance the radar was monitoring pixel sizes of $7 \times 7 \mathrm{~m}$ to $9 \times 9 \mathrm{~m}$. By placing the radar so far away it could monitor the entire east wall with a fifteen minute sweep and was still able to pick up large scale movement related to geological structures, as seen in Figure 15. The image indicates outward movements of up to $7 \mathrm{~mm}$ between the two splay faults. The horizontal lines of dark pixels one third the way up the pixel image corresponds to movement of the mesh on a rock catch fence. Interestingly, the finer mesh hung over Matt's Block, refer to Figure 9, never indicated any movement by the radar; possibly due to being in a higher degree of tension.

Only during periods of particularly heavy rain was the radar data unusable. For the most part, even in wet conditions the radar remained largely unaffected by rainfall.

Over the last couple of years it has become common practice at Savage River that following a blast on the eastern side of the pit that there was to be no work carried out under the east wall for at least 12 hours. This translated into stopping at 2:30 pm for a blast and not returning to work until the next morning in daylight, when a visual inspection was made. The radar gave the geotechnical department the ability to monitor the wall for an hour or two following a blast and to then reopen this work area when satisfied that any reaction to the blast had settled down. 


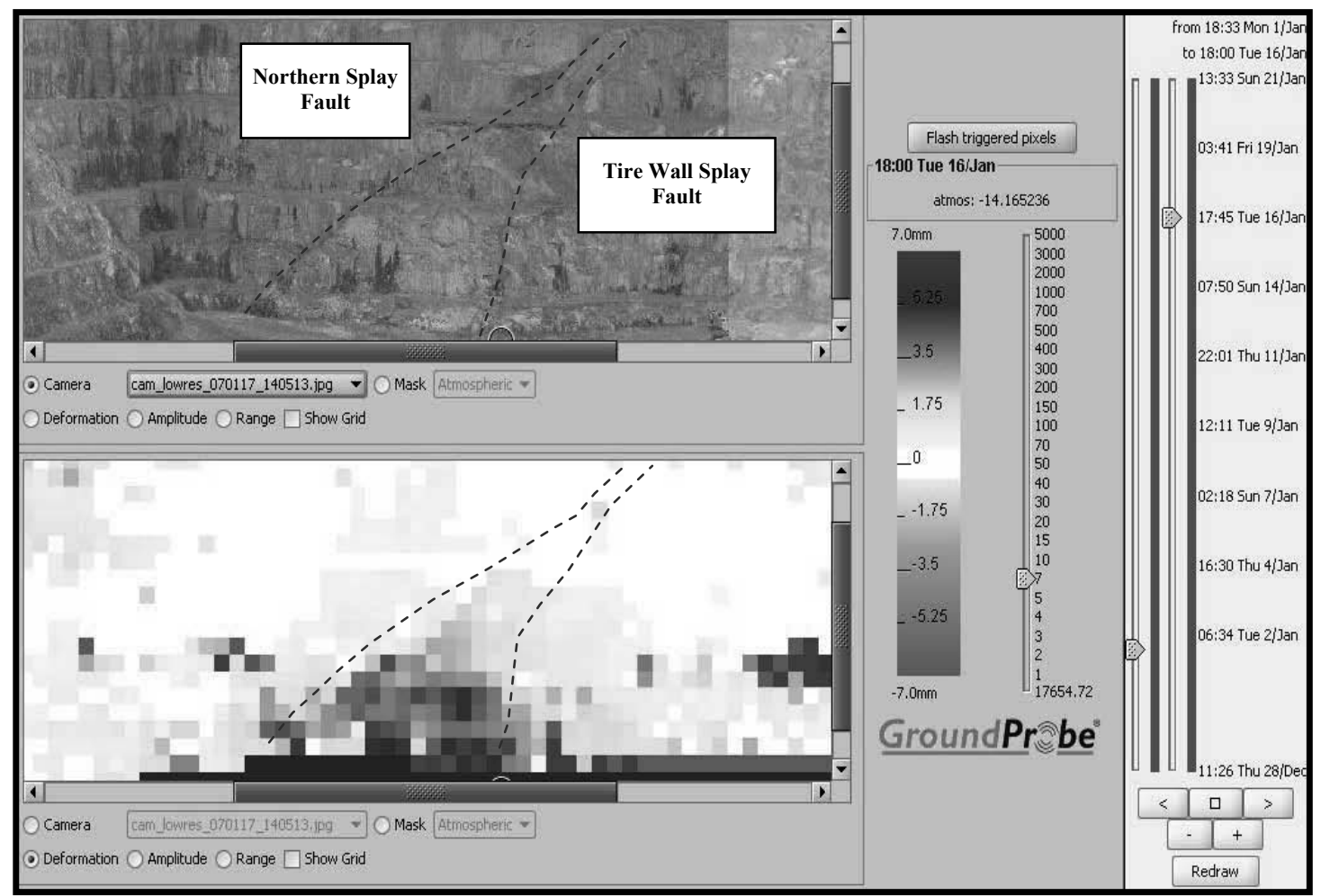

Figure 15 East wall splay fault movement area

Two additional problems were encountered with the radar. The first was related to interference from movements of the mesh in the rock catch fences. These movements could not be distinguished from movements of loose rock related to the relaxation of the batter crest, which is considered to be a major source of rockfall activity. The second issue came about due to movements with the radar pad. If the radar base begins moving, even minute amounts, the radar images begin showing halo effects, which can be interpreted as base movement, and these eventually override any movement being recorded on the opposite wall. With the progressive deepening of the pit and renewed mining along the pit crest in the vicinity of the radar, the base began slowly creeping, which made the crest locations for the radar untenable.

With the re-focus of mining on the upper west wall as part of the mine life extension the activities in the base of the pit have slowed. Ore is now only mined as needed to feed the crusher, rather than placing it on the closure plan stockpiles. With the cable bolting of the east wall also nearing completion the radar was demobilised. Although ABM was not able to utilize the radar to monitor small rockfalls, the unit proved useful in monitoring larger scale rock movement activity and will be consider again for deployment if personnel and equipment needs to continually work under a moving wall that can not adequately be monitored by the ATS system.

\section{Summary}

Due to the complex nature of rock falls and wall instability in general it must be recognised that there is no single control that, when applied, will eliminate rockfall risk completely. As such ABM have embarked on a multifaceted approach to identify solutions across the entire hierarchy of controls, with the intent of managing the risk to an acceptable level in the short term and the vision of removing the risk completely by carrying out all activities in the vicinity of the high wall remotely.

\section{References}

Hutchison, B.J. (2000) Geotechnical Aspects of the Savage River Iron Ore Mine Tasmania, Journal and News of the Australian Geomechanics Society, Volume 35, No 2.

Hutchison, B.J., Dugan, K. and Coulthard, M.A. (2002) Analysis of Flexural Toppling at Australian Bulk Mineral's Savage River Mine, GeoEng2000, Melbourne, Australia, November 2000. 